\title{
Surviving Major Trauma with Hemipelvectomy
}

\author{
Christina Müller-Höcker*, Natalie Chuck and Urs Pietsch \\ Department of Anesthesiology, Kantonspital St. Gallen, Switzerland
}

Submission: December 02, 2016; Published: January 24, 2017

*Corresponding author: Christina Müller-Höcker, Department of Anesthesiology, Kantonspital St. Gallen, Switzerland,

Email: Christina.muellerhoecker@googlemail.com

\begin{abstract}
Traumatic hemipelvectomy is a life threatening, however rare injury associated with high lethality. It comes along with excessive blood loss, related hemodynamic instability and injuries of the genitor-urinary system or the rectum. The real incidence is unknown because most patients die before reaching the hospital. The treatment requires a rapid, multidisciplinary team approach focused on hemorrhage control to correct coagulopathy and clear persistent signs of tissue hypoperfusion to save the patient's life [1]. Improvements in prehospital rescue systems and initial trauma response have resulted in increased chances of survival. Most survivors are young, healthy individuals, who are able to tolerate massive hemorrhage and soft-tissue destruction [2-6]. We present a case of an open fracture of the ileosacral joint, wide open symphysis, complete hemipelvectomy and severe soft tissue trauma, including a decollement around the pelvis and the left abdomen.
\end{abstract}

\section{Case Report}

A case of an 18-year-old woman surviving traumatic hemipelvectomy is presented. The woman was involved in a high speed motorcycle accident. She was caught by a gusting wind and thereby accidently left the road by crossing the midline onto the oncoming lane and crashed frontally into an oncoming car. In primary survey on scene the assessment following Adult Trauma and life Support (ATLS) guidelines revealed an AB stabile and cardial compensated patient with Glasgow Coma Scale (GCS) of 15 points, despite a considerable blood loss, an unstable pelvis and a cold, mottled, pulse less left leg. Her lower left limb showed an open third degree femur-fracture, as well as a grotesque deformation of the lower limb and left hemi-abdomen. The woman was wearing full motorcycle clothing and a helmet. On site the thorax only showed some excoriations and no instability, as far as visible. Because of the extensive trauma which came along with fulminate pain, anesthesia was introduced by the flying doctor to perform an appropriate pain management. The woman was managed with fluid to maintain a hemodynamic stability. Hemorrhage control was obtained with compression of the wounds and she was then transferred by HEMS to the next trauma centre. There were no further diagnoses set in the secondary survey.

Upon arrival at the trauma center she was hemodynamically unstable, due to a covered aortic rupture loco typical, an internal amputation atthepelviclevelwith consecutive massivehemorrhage
(Figure 1a,1b), separation of the symphysis (Figure 2 \& 3), an open pelvic fracture (Figure $2 \& 3$ ) and an open femur fracture (Injury severity score $=59$ ). Explicitly the whole body trauma computer tomography revealed the following principal diagnosis. A covered aortic rupture loco typical, an internal amputation at the pelvislevel with avulsion of the left a iliaca external with a consecutive massive bleeding (Figure 1a). Separation of the symphysis, an open pelvic fracture with gas inclusion at the caudal spinal cord coming from a SWK4/5 fracture, and an open femur fracture was seen (Figure $2 \& 3$ ). Additionally there was no perfusion seen in the angiography providing blood for the left lower limb, which was actively bleeding at that moment. An urgent angiogram revealed occlusion of the left external iliac artery. There was a haemathothorax seen on the left side of the thorax, shifting the trachea and the esophagus to the right, however without leading to oxygenation problems. No intracranial pathology was found in the computer tomography. Immediate surgical homeostasis and debridement was attempted for primary damage control. To save the patient's life it was necessary to perform aggressive surgery with a complete amputation of the left hemi pelvis including the left lower limb. Additionally, a skin flap was provided. A limbsaving procedure would have endangered the patient's life. Furthermore, the patient underwent embolization of the left common iliac artery and vein and a Thoracic Endovascular Aortic Repair (TEVAR) of the aortic rupture. 


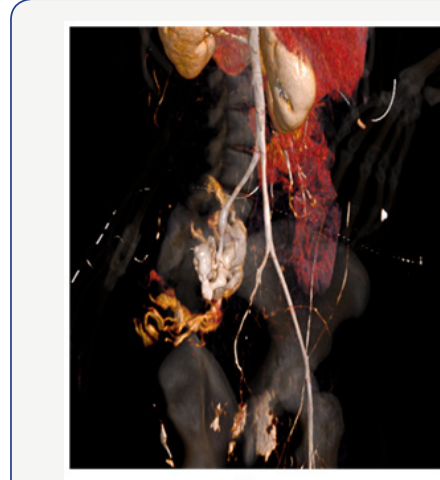

(a)

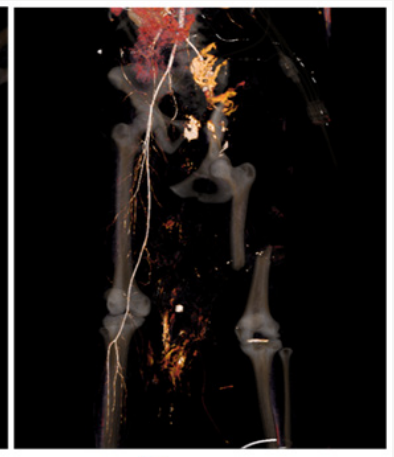

(B)
Figure 1: CT scan and angiography: internal amputation at the pelvis- level with avulsion of the left A. iliaca external with a consecutive massive bleeding.

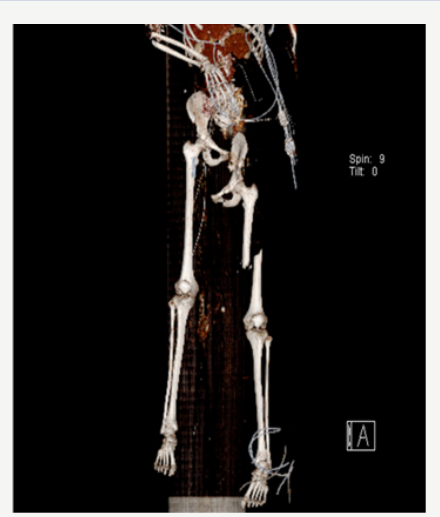

Figure 2: CT scan: separation of the symphysis, open pelvic fracture and open femur fracture.

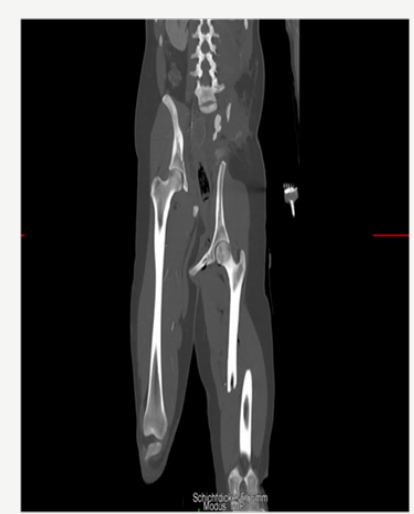

Figure 3: CT scans: 3D reconstruction of the pelvis.

In the further hospital course, frequent second-look operations and numerous revisions of the soft tissue injury, reconstructive surgery and dedicated surgical care to avoid septic complications were needed. In the following the woman was throughout in a stable mental state, nevertheless psychological assistance was directly started after completion of the first surgery. After finalization of the operative therapy and coverage of the skin defect the woman was transferred to a rehabilitation centre 9 weeks after the accident (Figure 4). She then was transferred to a trauma centre to adjust an artificial limb. In summary, this patient is one of the few survivors of an ISS of 59 points reported in the world literature [2-4]. She was able to survive a major trauma by accurate and rapid early management, rapid transport to the operating room and an aggressive surgical approach all contributed to survival.

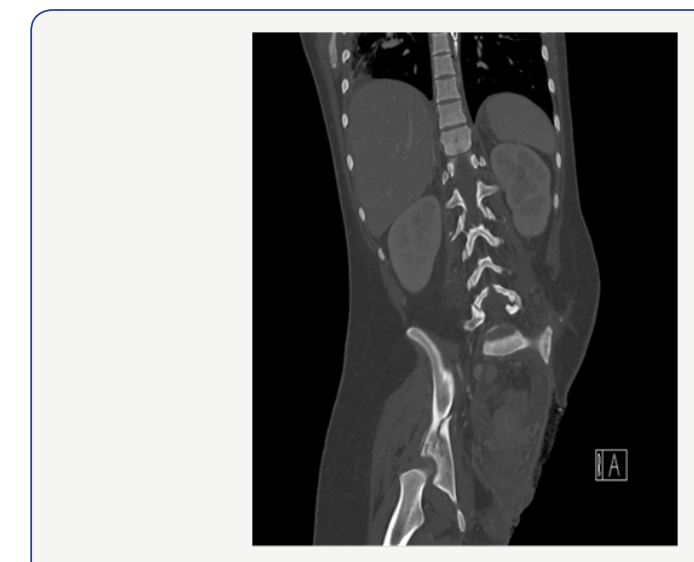

Figure 4: CT scan: final CT- control after finalisation of the operative therapy and coverage of the skin- defect.

\section{Conclusion}

The leading injury was a traumatic hemipelvectomy coming along with the disruption of the pelvic neurovascular integrity and a covered aortic rupture loco typico. The accepted definition of traumatic hemipelvectomy is as follows: unstable ligament us or osseous hemi pelvic fracture/amputation, (open or closed) accompanied by an injury with rupture of the pelvic neurovascular bundle [5]. Most survivors are young, healthy individuals, who are able to tolerate massive hemorrhage and soft-tissue destruction. When the criteria or traumatic hemipelvectomy are fulfilled, surgical completion of the hemipelvectomy is mandatory to safe a patient's life $[4,6]$. Whereas mortality in open pelvic fractures is around $40 \%$, it is 60 to $100 \%$ in traumatic hemipelvectomies, and bleeding is the main cause of death $[3,6]$. In conclusion, traumatic hemipelvectomy is a rarely seen, often fatal injury which requires immediate life support and surgery. This injury always requires a rapid, multidisciplinary team approach, including an orthopedist, vascular surgeon, general surgeon, urologist and anesthesiologist focused on hemorrhage control to correct coagulopathy and clear persistent signs of tissue hypo perfusion. Furthermore, the involvement of rehabilitation specialists is advantageous for personal well-being and social reintegration. Eighty percent of injuries occur as a result of motorcycle accidents [3]. Although hemipelvectomy is a devastating injury, patients can be successfully rehabilitated to an active and productive role in society.

\section{References}

1. Kayalar M, Gurbuz Y, Sugun TS, Kaplan I (2014) Traumatic hemipelvectomy: case presentation. Acta Orthop Traumatol Turc 48(2): 226-230. 
2. Schoderbek RJ, Battaglia TC, Dorf ER, Kahler DM (2005) Traumatic hemipelvectomy: case report and literature review. Arch Orthop Trauma Surg 125(5): 358-362.

3. Lasurt S, Combalia-Aleu A (2010) Complete traumatic hemipelvectomy Report of a case after 19 years of follow-up. Injury 41(8): 874-882.

4. Klasen HJ, Duis HJT (1989) Traumatic hemipelvectomy. The Journal of Bone and Joint Surgery 71(2): 291-295.

This work is licensed under Creative Commons Attribution 4.0 License

DOI:10.19080/JAICM.2017.01.555567
5. Pohlemann T, Paul C, Gänsslen A, Regel G, Tscherne H (1996) Traumatic hemipelvectomy. Experiences with 11 cases. Der Unfallchirurg 99(4): 304-312.

6. Yalniz E, Ciftdemir M, Durukan T (2007) Traumatic Hemipelvectomy: A Case Report and a Review of the Literature. European Journal of Trauma and Emergency Surgery 33(3): 306-309.

\section{Your next submission with Juniper Publishers will reach you the below assets}

- Quality Editorial service

- Swift Peer Review

- Reprints availability

- E-prints Service

- Manuscript Podcast for convenient understanding

- Global attainment for your research

- Manuscript accessibility in different formats

( Pdf, E-pub, Full Text, Audio)

- Unceasing customer service

Track the below URL for one-step submission https://juniperpublishers.com/online-submission.php 